Research Paper

\title{
Clinical and Diagnostic Significance of Homerl in hepatitis B virus-induced Hepatocellular Carcinoma
}

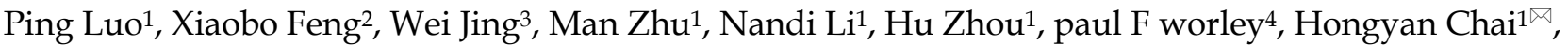 \\ Jiancheng $\mathrm{Tu}^{1 凶}$ \\ 1. Department of Clinical Laboratory Medicine \& Center for Gene Diagnosis, Zhongnan Hospital of Wuhan University, Wuhan 430071, China; \\ 2. Department of Pain, Zhongnan Hospital of Wuhan University, Wuhan 430071, China; \\ 3. Department of Clinical Laboratory, First Affiliated Hospital of Zhengzhou University, Henan, 450000, China. \\ 4. Department of Neuroscience, Johns Hopkins University School of Medicine, Baltimore, MD 21205. \\ $\square$ Corresponding authors: Jiancheng Tu \& Hongyan Chai, E-Mail: jianchengtu@whu.edu.cn; chy1127@sina.com \\ (c) Ivyspring International Publisher. This is an open access article distributed under the terms of the Creative Commons Attribution (CC BY-NC) license \\ (https://creativecommons.org/licenses/by-nc/4.0/). See http://ivyspring.com/terms for full terms and conditions.
}

Received: 2017.08.08; Accepted: 2017.12.02; Published: 2018.01.11

\begin{abstract}
Background: Hepatocellular carcinoma (HCC) is a malignant tumor worldwide. Attributed to the lack of early diagnosis index, most patients are diagnosed in their late stage. Homerl, as a member of scaffold protein family, is made up of two different isoforms: Homerla and Homerlb/c. More and more evidences show that Homerl is dysregulated in cancers. Here, in this study, we investigated the expression profile, clinical, diagnostic and prognostic significance of Homerl in hepatitis B virus-induced HCC (HBV-HCC).

Methods: We first tested the expression of Homerl in $\mathrm{HCC}$ cell lines by quantitative real-time PCR (qRT-PCR), western blot. Then, 86 pairs of tumorous and adjacent normal tissues from HCC together with a total number of $\mathbf{2 4 5}$ peripheral blood samples were enrolled to check the expression levels of Homerl by quantitative real-time PCR (qRT-PCR).

Results: The results revealed that the levels of Homerl were both downregulated in $\mathrm{HCC}$ cell line and tissue and were associated with tumor size, but were not related to the prognosis of HBV-HCC. Receiver-operating characteristic curve analyses indicated that the sensitivity of Homerl to differentiate HCC patients from the controls was high to $100.0 \%$ and the combination of Homerl and AFP got a higher prediction value of HCC (AUC=0.890).
\end{abstract}

Conclusion: Our data highlighted that Homerl played a critical role in $\mathrm{HCC}$ tumorigenesis and might be a potential diagnostic marker for HCC.

Key words: Homer1; HCC; Tumorigenesis; Diagnosis: Down-regulated

\section{Introduction}

Hepatocellular carcinoma (HCC) is one of the sixth most common and aggressive malignancies, and ranks as the third leading cause of cancer-related death all over the world [1,2]. Although many factors can accelerate the development of HCC, it has been reported that cirrhosis is the leading risk factor for HCC[3], and hepatitis B virus (HBV) infection represents the majority of cirrhosis cases[4]. Over the past 20 years, the mortality rate resulted from HCC has rose significantly [5]. At present, the most common clinical biomarkers to diagnose HCC is afetoprotein (AFP), however, the sensitivity of serum AFP is only $39-65 \%[6,7]$, leading to the patients that with early stage HCC undiagnosed. It is reported that serum AFP levels may remain normal even in 15-30\% of advanced HCC [8]. In addition, AFP level can increase in benign liver diseases, such as hepatitis and cirrhosis[9]. Therefore, the development of non-invasive biomarkers with high sensitivity and specificity for the early detection of HCC would be highly beneficial.

It is known to us all that Homer protein families are made up of three subtypes: Homer1, Homer2, and Homer3 [10, 11]. Homer1 as a member of Homer families consists the following two different isoforms: Homer1a and Homer1b/c. Homer1a which is the first 
identified Homer protein is a short variant of Homer1 [12]. In contrast to homerla, the long form Homer1b/c contains additional amino acids at the $\mathrm{C}$ terminus and is consistently expressed[13]. Intracellular calcium, as a versatile second messenger plays a vital role in tumor cells, through apoptosis, proliferation, invasion and metastasis [14, 15]. Homer1 has been reported to interact directly or indirectly with $\mathrm{Ca}^{2+}$ signaling proteins, such as the canonical TRPC (transient receptor potential channel) [16], STIM1 (stromal interaction molecule1)[17], $\mathrm{IP}_{3} \mathrm{R}$ (inositol-1,4,5-triphosphate) [18] and Orai1 [17]. Furthermore, Homer1 is involved in modulating the trafficking of mGluR5 (metabotropic glutamate receptor 5) from the cytoplasma to the plasma membrane[19] and activity of mGlu5 might regulate cell survival in HCC[20]. Thus, we assumed that there was a correlation between Homer1 and tumors. Wu et al.[21] found that the expression of Homer1 in intrahepatic cholangiocarcinoma was higher than that in the adjacent tissues and its expression was negatively correlated with the 5 year survival rate of the patients. Meanwhile, Shin et al.[22] revealed that various tumor cells (HeLa, HCT116, HEK 293, DU145, and A549) originated from tissues of cervix, colon, kidney, and lung express the significant amounts of Homer1 protein, indicating that Homer1 may play some roles in tumorigenesis. However, the role of Homer1 in HBV-HCC has not been previously described.

In this study, we set out to evaluate the expression profile of Homer1 in HBV-HCC patients, then to analyze the correlation between Homer1 expression and clinicopathological characteristics of patients with HBV-HCC, and to explore whether Homer1 could be a new biomarker for HBV-HCC.

\section{Materials and Methods}

\section{Sample collection and ethics statement}

Eighty-six HBV-HCC (79 men and 7 women, mean age $58 \pm 10$ ) tissues and their adjacent normal tissues (located $>3 \mathrm{~cm}$ away from the tumor) were collected from Zhongnan hospital of Wuhan university between 2012 and 2017. A number of 245 individuals' blood samples were also recruited in the same hospital during 2016, including 80 healthy controls, 52 patients with hepatitis B, 53 HBV-related cirrhosis patients, and $60 \mathrm{HBV}-\mathrm{HCC}$ patients. We chose all subjects based on medical or pathology reports. All the patients included in our experiment were HBsAg positive and without any other liver diseases, such as alcoholic, autoimmune, hepatitis $C$ and metabolic liver diseases. Patients who underwent any chemotherapy or radiotherapy were not included in our study. Healthy blood samples were got from donors who underwent routine medical examinations at the Physical Examination Center. The study protocol was approved by the Medical Ethical Committee of Zhongnan Hospital of Wuhan University (ethical approval 2013059, April 2013).

\section{Isolation of peripheral blood leukocytes}

One milliliter peripheral blood collected in EDTA tubes was placed directly into RNase-free tubes, then 3 milliliter red blood cell lysis buffer was added into it and then it was put on ice for 30 minutes. Thirty minutes later, the diluted blood was centrifuged at $12,000 \mathrm{~g}$ for $10 \mathrm{~min}$ at $4^{\circ} \mathrm{C}$. After centrifugation, the supernatant was discarded. Subsequently, the deposition was washed with red blood cell lysis buffer to remove plasma and erythrocyte by centrifuging at 12,000 g for $5 \mathrm{~min}$ at $4^{\circ} \mathrm{C}$. The supernatant was discarded, and the cell pellet was suspended in Trizol reagent. Then these samples were stored at $80^{\circ} \mathrm{C}$ until RNA extraction.

\section{RNA extraction and reverse transcription}

Total RNA was extracted from tissues and peripheral blood leukocytes using Trizol reagent (Invitrogen, Carlsbad, CA, USA). Nanodrop 2000 spectrophotometer (Thermo Scientific Inc., Waltham, MA, USA) was used to measure the concentration of the RNA. $1 \mu \mathrm{g}$ RNA was reversely transcribed in a final reaction volume of $20 \mu \mathrm{L}$ using PrimescriptTM RT reagent Kit with gDNA Eraser (Takara, Japan) and the primer used for RT was random hexamer. Reverse transcription conditions were as follows: $42^{\circ} \mathrm{C}$ for 2 min, and then $37^{\circ} \mathrm{C}$ for $15 \mathrm{~min}, 85^{\circ} \mathrm{C}$ for $5 \mathrm{sec}$. All cDNA samples were stored at $-80^{\circ} \mathrm{C}$ before real-time PCR analysis.

\section{Real-Time Polymerase Chain Reaction}

The expression of Homer1 was measured on the Bio-Rad CFX96 (Bio-Rad Laboratories, Inc., Hercules, CA, USA) using SYBR-Green I Premix Ex Taq following manufacturer's instructions. GAPDH was chosen as endogenous control gene to normalize Homer1 levels. The sequences of the PCR primers for GAPDH and Homer1 were as follows: 5'AGAAGGCTGGGGCTCATTTG-3' (sense) and 5'GCAGGAGGCATTGCTGATGAT-3' (anti-sense) for GAPDH, 5'-GATCCTGCCTAGCCTTCT-3'(sense) and 5'-GGAGCGAGCAACCAAACG-3' (anti-sense) for Homer1. Real-time PCR was performed in a volume of $20 \mu \mathrm{L}$ including $1.5 \mu \mathrm{L}$ cDNA, $10 \mu \mathrm{L}$ SYBR Green $\mathrm{mix}, 1.6 \mu \mathrm{L}$ gene-specific forward and reverse primers $(10 \mu \mathrm{M})$, and $6.9 \mu \mathrm{L}$ nuclease-free water. The reactions started at $95^{\circ} \mathrm{C}$ for $5 \mathrm{~min}$, followed by 40 cycles of 95 ${ }^{\circ} \mathrm{C}$ for $30 \mathrm{~s}, 62{ }^{\circ} \mathrm{C}$ for $30 \mathrm{~s}$ and $72{ }^{\circ} \mathrm{C}$ for $30 \mathrm{~s}$. All reactions were amplified in duplicate with no-template 
controls included. The relative expression levels of Homer1 were calculated using $2^{-\Delta \mathrm{Ct}}$.

\section{Cells and cell culture}

Human HCC cell lines HepG2 were bought from the China Center for Type Culture Collection (CCTCC, Wuhan, China), the normal human hepatocyte cell line L-02 were purchased from the Procell Inc. (Wuhan, China). HCCLM-9 were maintained at our laboratory. All the Cells were cultured in RPMI 1640 medium (Gibco, USA) supplemented with $10 \%$ fetal bovine serum (FBS, Gibco, USA), $50 \mathrm{U} / \mathrm{ml}$ penicillin and $50 \mathrm{U} / \mathrm{ml}$ streptomycin in flasks at $37{ }^{\circ} \mathrm{C}$ in a humidified atmosphere of $5 \% \mathrm{CO}_{2}$.

\section{Western blot analysis}

Homer1 protein expression was detected by western blot analysis. The stable cells were lysed using RIPA lysis buffer in the presence of PMSF proteinase inhibitor (Beyotime, China) and the lysates were harvested by centrifuging $(12,000 \mathrm{rpm})$ at $4^{\circ} \mathrm{C}$ for $30 \mathrm{~min}$. Protein samples of approximately $40 \mathrm{ug}$ were electrophoresed on $12 \%$ sodium dodecyl sulphate polyacrylamide gel and were transferred onto polyvinylidene difluoride (PVDF) membrane. After blocking the nonspecific binding sites for $1 \mathrm{~h}$ with $5 \%$ non-fat milk in PBST, the membrane were incubated at $4^{\circ} \mathrm{C}$ overnight with a rabbit polyclonal antibody against Homer1 (1:3, 000 dilution). GAPDH was used as a loading control. After incubated with secondary antibody for $1 \mathrm{~h}$ at room temperature, the signals were detected by the enhanced chemiluminescence reagents (ECL) (Beyotime, China). The Image J software was used to quantify the optical density of each band.

\section{Statistical Analysis}

Statistical analyses were performed using SPSS 17.0 software (SPSS, Chicago, IL, USA) and GraphPad Prism 5 software (GraphPad software, La Jolla, CA, USA). Normally distributed data were presented as mean \pm standard deviation (SD). Skewed data were described by the median and inter-quartile range. The Shapiro-Wilk test was done to check the normality of the distribution. Student's $\mathrm{t}$ test was operated to detect normally distributed data, while non-normally distributed variables were analyzed by KruskalWallis variance analysis. Categorical variables were tested using Chi-square test. One-way ANOVA was used for the comparison among multiple groups if the variance was homogeneous. ROC curves were constructed to evaluate the diagnostic value of Homer1 as a biomarker. Samples with $\mathrm{Ct}$ value $>37$ were removed from the study for its uncertainty. All statistical tests were two-sided and $P<0.05$ was considered statistically significant.

\section{Results}

\section{Homerl expression in HCC cell lines}

To explore the association between Homer1 and HCC, we tested the expression levels of Homer1 in one normal cell line L-02 and two HCC cell lines (Hep-G2, and HCCLM-9) both in RNA and protein level. The results revealed that Homer1 were down expressed in HCC cell lines than that in normal cell line (Figure. 1).

\section{Homerl expression in HBV-HCC tissues}

RT-qPCR was performed to evaluate the expression levels of Homer1 in HBV-HCC tissues and adjacent normal liver tissues derived from 86 HBV-HCC patients. It is reported that GAPDH was the most frequently used reference gene for RT-qPCR analysis in HCC[23], so we chose GAPDH as our reference gene. No significant alteration of GAPDH expression levels between HBV-HCC tumor tissues and matched paracancerous tissues were existed $(P=0.125)$. The expression level of Homer1 was significantly lower than that in matched adjacent tissues $(P<0.001$; Figure 2A). Waterfall plot showed that the expression of Homer1 was downregulated in $62.8 \%(54 / 86)$ of HCC tissues and Homer1 was reduced by at least twofold in $48.8 \%(42 / 86)$ of the HCC patients (Figure 2B).

\section{Correlation between Homer 1 and clinic features}

We analyzed the relationship between Homer1 levels and clinicopathological characteristics of the 86 HBV-HCC patients. No significant correlations were found between Homer1 levels and gender, age, smoking, alcoholism, TNM (tumor-node-metastasis stage), HBV DNA levels, cirrhosis, AFP (a-fetoprotein), ALT (alanine aminotransferase), AST (aspartate aminotransferase) and GGT ( $\gamma$-glutamyl transferase) $(P>0.05)$, whereas the levels of Homer1 were significantly associated with tumor sizes. $(P=0.040)$ (Table 1)

\section{Association between Homerl levels and patients' survival}

To explore the prognostic value of Homer1 in HBV-HCC, we assessed the relationship between Homer1 expression and overall survival (OS) in 53 patients. Patients were divided into two group, and 24 of them were in the high Homer1 group, 29 patients were in the low group. The Kaplan-Meier plots and Log-rank tests were applied. Unfortunately, no association between Homer1 expression and overall survival was found. $(P=0.193$, Figure 3$)$ 
A

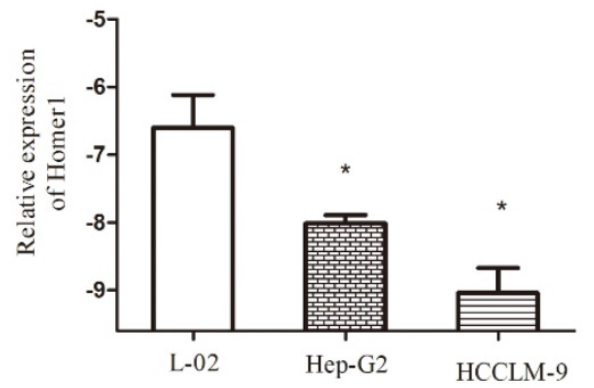

B

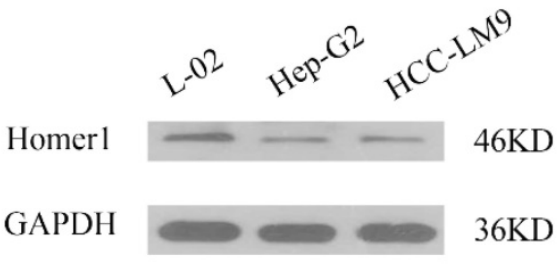

Figure 1. Evaluation of Homerl in two HCC cell lines compared to a normal liver cell line L-02.

A

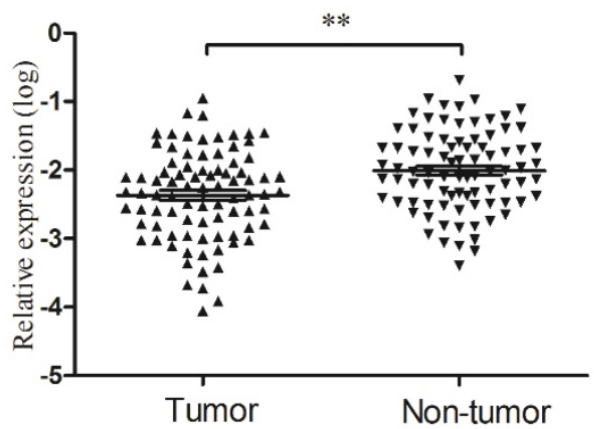

B

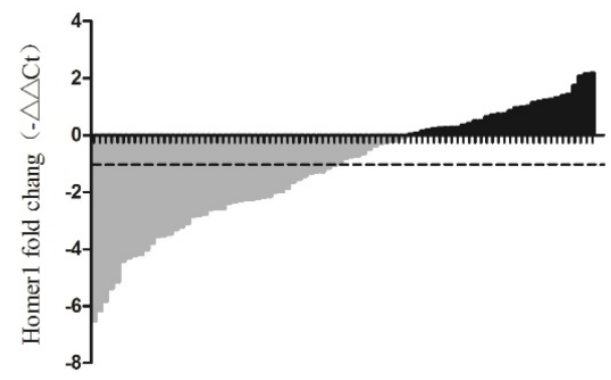

Figure 2. Homerl expression in HCC tissues. The relative Homerl expression was determined by RT-qPCR.

\section{The expression of Homerl in peripheral blood among subgroups}

In addition to evaluate Homer1 expression in cell lines and tissues, we also tested its expression in peripheral blood in $60 \mathrm{HBV}-\mathrm{HCC}$ patients, 53 cirrhosis patients, 52 hepatitis $\mathrm{B}$, and 80 control cases. The main demographic and clinical characteristics of the studied subjects were summarized in Table 2 . There were no differences in risk factors including gender, age, smoking, alcoholism whereas a significant difference in ALT, AST, TBIL, GGT and GLU among the groups were found.

As shown in Figure 4, we found that the expression of Homer1 in HBV-HCC was lower than that in hepatitis $\mathrm{B}$, cirrhosis and control groups (HBV-HCC vs cirrhosis: $P<0.05$; HCC vs hepatitis B: $P<0.001$; HCC vs the controls: $P<0.001)$. Despite that no significant difference was observed when we compared the expression levels of Homer1 in other three subgroups (cirrhosis, hepatitis B and the controls), the level of Homer1 had a decline tendency from control cases, HBV, cirrhosis to HCC which was in accordance with the development hallmark of HCC.

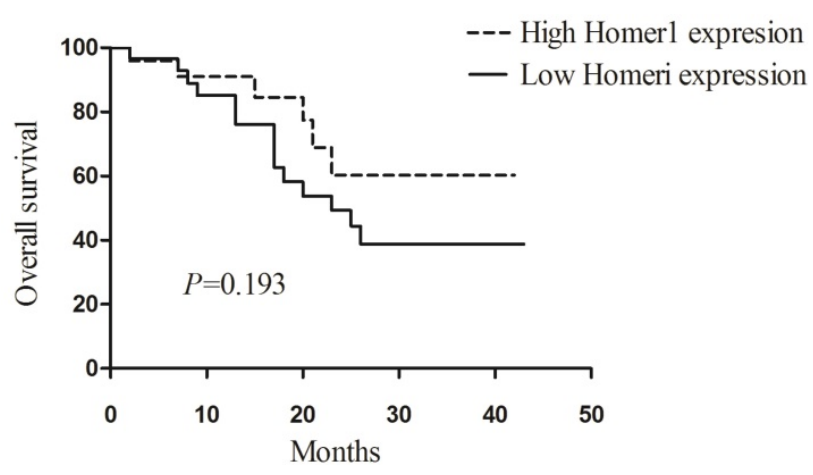

Figure 3. Association between the expression of Homerl and prognosis in HBV-HCC.

\section{Diagnostic value of Homerl in peripheral blood as a biomarker}

ROC curve analysis was carried out to evaluate the diagnostic value of Homer1 in HBV-HCC. Results revealed that the diagnostic value of Homer1 in discriminating HBV-HCC from hepatitis B and cirrhosis was not obvious (Figure 5 A-B). However, Homer1 can discriminate HBV-HCC patients from the controls with a sensitivity of $100.0 \%$ based on the cutoff value of -2.483 (AUC $=0.724,95 \%$ CI: $0.634-0.814$ ) (Figure 5C). The combination of Homer1 and AFP possessed a moderate ability for discriminating HCC 
patients from the controls with an area equal to 0.890 (95\% CI: 0.81-0.969) (Figure 5D and Table 3).

Table 1. Association between Homerl expression and clinical characteristics in HCC

\begin{tabular}{|c|c|c|c|c|}
\hline \multirow[t]{2}{*}{ Characteristics } & \multirow[t]{2}{*}{$\mathbf{N}$} & \multicolumn{3}{|c|}{ Homer1 relative expression(log) } \\
\hline & & Mean \pm SD & $t$ & $P$ \\
\hline Tissue $^{* *}$ & & & -5.378 & 0.0001 \\
\hline $\mathrm{HCC}$ & 86 & $-2.34 \pm 0.62$ & & \\
\hline $\begin{array}{l}\text { Adjacent non-cancerous } \\
\text { liver }\end{array}$ & 86 & $-2.06 \pm 0.56$ & & \\
\hline Gender & & & -0.749 & 0.456 \\
\hline Male & 79 & $-2.39 \pm 0.67$ & & \\
\hline Female & 7 & $-2.19 \pm 0.46$ & & \\
\hline Age & & & 1.727 & 0.088 \\
\hline$<55$ & 44 & $-2.25 \pm 0.67$ & & \\
\hline$\geqq 55$ & 42 & $-2.49 \pm 0.63$ & & \\
\hline Alcoholism & & & -1.558 & 0.124 \\
\hline Negative & 40 & $-2.48 \pm 0.66$ & & \\
\hline Positive & 26 & $-2.22 \pm 0.64$ & & \\
\hline Differentiation & & & 1.376 & 0.173 \\
\hline High/ Moderate & 62 & $-2.41 \pm 0.69$ & & \\
\hline Low & 12 & $-2.12 \pm 0.55$ & & \\
\hline Size* & & & 2.092 & 0.040 \\
\hline$<5 \mathrm{~cm}$ & 23 & $-2.11 \pm 0.53$ & & \\
\hline$\geqq 5 \mathrm{~cm}$ & 56 & $-2.45 \pm 0.70$ & & \\
\hline TNM stage & & & -0.533 & 0.596 \\
\hline $\mathrm{I} \sim \mathrm{II}$ & 28 & $-2.37 \pm 0.66$ & & \\
\hline III $\sim \mathrm{IV}$ & 40 & $-2.28 \pm 0.70$ & & \\
\hline HBV DNA (IU/ml) & & & -1.366 & 0.179 \\
\hline$<500$ & 20 & $-2.56 \pm 0.60$ & & \\
\hline$\geqq 500$ & 27 & $-2.32 \pm 0.60$ & & \\
\hline Cirrhosis & & & -0.332 & 0.741 \\
\hline Negative & 8 & $-2.28 \pm 0.79$ & & \\
\hline Positive & 41 & $-2.36 \pm 0.65$ & & \\
\hline $\mathrm{AFP}(\mathrm{ng} / \mathrm{l})$ & & & -1.842 & 0.069 \\
\hline$<200$ & 40 & $-2.51 \pm 0.66$ & & \\
\hline$\geqq 200$ & 41 & $-2.24 \pm 0.65$ & & \\
\hline $\operatorname{ALT}(\mathrm{U} / \mathrm{l})$ & & & -1.958 & 0.054 \\
\hline$<46$ & 51 & $-2.48 \pm 0.68$ & & \\
\hline$\geqq 46$ & 35 & $-2.20 \pm 0.60$ & & \\
\hline AST (U/1) & & & -1.534 & 0.129 \\
\hline$<46$ & 49 & $-2.46 \pm 0.68$ & & \\
\hline$\geqq 46$ & 37 & $-2.24 \pm 0.61$ & & \\
\hline GGT (U/1) & & & 0.965 & 0.338 \\
\hline$<55$ & 35 & $-2.28 \pm 0.69$ & & \\
\hline$\geqq 55$ & 51 & $-2.42 \pm 0.64$ & & \\
\hline
\end{tabular}

Data are shown as mean \pm standard deviation. Since we failed to collect all characteristics of the patients, the total number may not be 86 . TNM,

tumor-node-metastasis. AFP, $\alpha$-fetoprotein; ALT, alanine aminotransferase; AST, aspartate aminotransferase; GGT, $\gamma$-glutamyl transferase; ${ }^{*} P<0.05,{ }^{* *} P<0.001$.

\section{Discussion}

HCC is one of the most common solid tumors with highly aggressive and poor prognosis worldwide [24]. In China, chronic HBV infection is a major contributing factor to HCC. In the past few years, numerous researches were performed to explore appropriate biomarkers to diagnose HCC [25]. However, there is still no reliable and effective non-invasive biomarkers. Presently, AFP is the most frequently used biomarker for the diagnosis of HCC, but the sensitivity and specificity remain unsatisfactory[26]. Hence, novel biomarkers to monitor the status of HBV infection patients and diagnose HCC at an early stage are urgently needed. Homer, as scaffold proteins, are newly studied in tumors. Considering its vital role in keeping the homestasis of calcium in intracellular, we believe that Homer1 is involved in tumorigenesis. Furthermore, $\mathrm{Wu}$ et al.[21] demonstrated that the expression of Homer1 in intrahepatic cholangiocarcinoma was higher than that in the adjacent tissues. Thus, it is particularly prospective to explore whether Homer1 can be a new biomarker for HCC.

Table 2. Characteristics of the studied participants

\begin{tabular}{|c|c|c|c|c|c|}
\hline & $\mathrm{HCC}$ & Cirrhosis & Hepatitis B & Control & \\
\hline Characteristics & $\mathrm{N}=60$ & $\mathrm{~N}=53$ & $N=52$ & $\mathrm{~N}=80$ & $P$ \\
\hline Gender & & & & & $0.589 \mathrm{a}$ \\
\hline Male & 48 & 41 & 43 & 56 & \\
\hline Female & 12 & 12 & 9 & 24 & \\
\hline Age & & & & & $0.839 \mathrm{a}$ \\
\hline$<55$ & 25 & 22 & 24 & 38 & \\
\hline$\geqq 55$ & 35 & 31 & 28 & 42 & \\
\hline Smoking & & & & & $0.943^{\mathrm{a}}$ \\
\hline Negative & 31 & 30 & 29 & 45 & \\
\hline Positive & 29 & 23 & 23 & 35 & \\
\hline Alcoholism & & & & & $0.943^{a}$ \\
\hline Negative & 41 & 38 & 35 & 57 & \\
\hline Positive & 19 & 15 & 17 & 23 & \\
\hline $\operatorname{ALT}(\mathrm{U} / \mathrm{l})$ & $48(27,78)$ ** & $25(20,37)$ * & $79(31,308)$ ** & $21(16,27)$ & $<0.001^{b}$ \\
\hline AST (U/1) & $50(32,100) * *$ & $36(25,45) * *$ & $50(31,96)$ ** & $22(20,26)$ & $<0.001^{b}$ \\
\hline TBIL $(\mu \mathrm{mol} / \mathrm{l})$ & $20(14,27)$ * & $23(13,34)$ ** & $22(13,79)$ * & $13(11,16)$ & $0.002^{\mathrm{b}}$ \\
\hline GGT (U/1) & $154(70,260)^{* *}$ & $39(22,128)^{*}$ & $\begin{array}{l}54(20,102)^{*} \\
*\end{array}$ & $22(18,37)$ & $<0.001^{b}$ \\
\hline GLU (mmol/l) & $5.2(4.6,6.0)^{*}$ & $4.8(4.2,6.1)$ & $4.5(4.2,5.2)$ & $\begin{array}{l}4.4 \\
(4.8,5.3)\end{array}$ & $0.010^{\mathrm{b}}$ \\
\hline
\end{tabular}

Data are shown as Median (25 Percentiles, 75 Percentiles). ${ }^{*} P<0.05,{ }^{* *} P<0.001$ vs

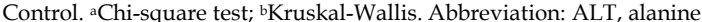
aminotransferase; AST, aspartate aminotransferase; GGT, $\gamma$-glutamyl transferase; GLU, glucose; AFP, a-fetoprotein.

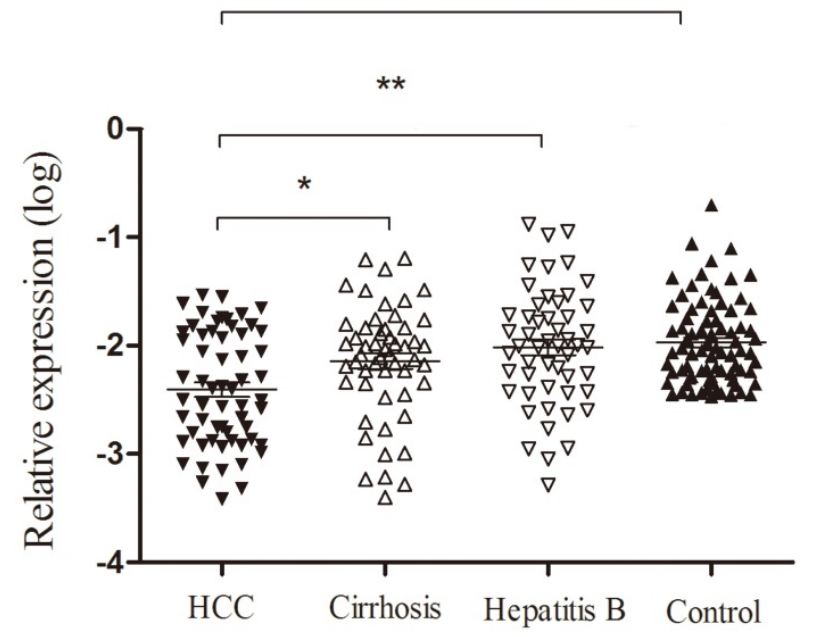

Figure 4. Homerl expression in peripheral blood among subgroups.

This is the first study to our knowledge to examine the role of Homer1 in HCC patients. We found that the levels of Homer1 were down expressed 
in HCC cell lines than that in normal cell line both in RNA and in protein level. In addition we also revealed that Homer1 were obviously downregulated in HCC tissues than that in corresponding noncancerous tissues. At the same time, our data indicated that Homer1 expression was highly related to tumor size and no association between Homer1 expression and overall survival was revealed. Peripheral blood appear to be well-suited for the study of gene expression [27], and it is well defined that HCC is systemic disease of the whole body. Besides, it is known to us that HCC is a prototype of inflammation-associated cancer that generally occurred on a background of chronic hepatitis, irrespective of the triggering etiology[28]. Thus we also detected the expression of Homer1 in peripheral blood leukocytes. In consistent with the tissues, the levels of Homer1 in HCC were much lower than that in cirrhosis, hepatitis B and the controls. Additionally, ROC curve suggested that the combination of Homer1 and AFP had a valid diagnostic value for HCC with the AUC of 0.890 .

There were some strengths of this study that should be paid attention to. First, we focused our study on the HBV-HCC, which makes the results more specific. Second we explored the expression level of Homer1 in cell lines, tissues and peripheral blood cells which greatly increased the research
A
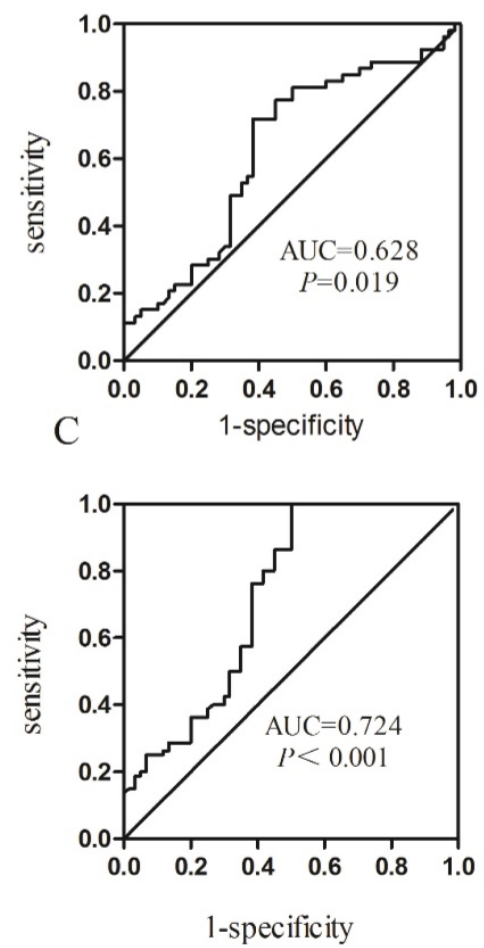

$\mathrm{B}$

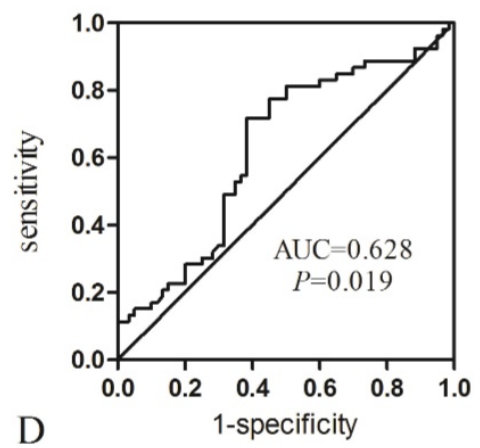

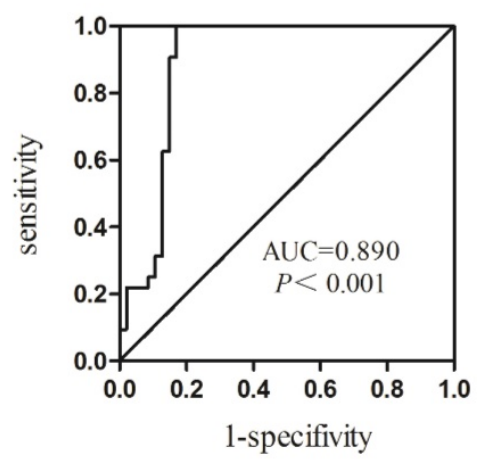

Figure 5. Receiver operating characteristic (ROC) curves. persuasive power. Third, the controls and the cases were matched on age, and the baseline characteristic distributions in our control group were similar to case group. Therefore, it is highly believed that selection bias was not significant and not likely to influence the results of our study. However, several limitations may exist in our study. First, the sample size of our study was not large, and the statistical power of the study may be limited. Second, the comparison of the expression level of Homer1 in HCC with that in adjacent non-cancerous lesion where chronic inflammation, including chronic hepatitis and liver cirrhosis, followed by regeneration existed [29] may affect our result.

Table 3. Presentation of the AUC of Homerl among subgroups

\begin{tabular}{llllll}
\hline Group & AUC & $\mathbf{9 5 \% C I}$ & $\boldsymbol{P}$ & Se(\%) & Sp(\%) \\
\hline HCC vs Cirrhosis & 0.628 & $0.523-0.733$ & 0.019 & 71.7 & 61.7 \\
HCC vs HBV & 0.685 & $0.587-0.784$ & $<0.001$ & 73.1 & 61.8 \\
HCC vs Controls & 0.724 & $0.634-0.814$ & $<0.001$ & 100.0 & 50.0 \\
HCC vs Controls* & 0.890 & $0.812-0.969$ & $<0.001$ & 100.0 & 83.0
\end{tabular}

Abbreviation: Se: Sensitivity; Sp: Specificity. ${ }^{*}$ Combination of Homer1 and AFP differentiates HBV-HCC patients from the controls.

In our study, we found a possible tumor suppressive role of Homer1 in HCC. In contrast to our study, Wu et al.[21] demonstrated that the expression of Homer1 in intrahepatic cholangiocarcinoma was higher than that in the adjacent tissues, suggesting an oncogenic role of Homer1. Interestingly, mRNA annexin A4 has been found to be decreased in prostate cancer [30] but increased in HCC[31] which revealed that there are genes act as oncogene or tumor suppressor in different cancers, we therefore deemed that Homer1 may play a diverse role in different tumors. $\mathrm{Ni}$ et al.[32] found that serum stimulated hepatocyte proliferation was dependent on calcium and depletion of calcium using thapsigargin or EGTA inhibited the proliferation. El Boustany et al.[33] demonstrated that TRPC6 was weakly expressed in isolated hepatocytes from healthy patients and expressed more strongly in tumoral samples from the liver of a cancer patient, indicating a role of calcium channels in liver oncogenesis. Homer, as a scaffolding protein can interact with a series of 
calcium channels, such as TRPC, STIM1, IP ${ }_{3} \mathrm{R}$ and Orai1. Thus, the hypothesis that Homer1 may inhibit the progress of HCC through interacting with calcium channels, then to mediate the intracellular $\mathrm{Ca}^{2+}$ concentration was made. However, the exact mechanism needs to be further researched.

In conclusion, we firstly identified that the expression of Homer1 was lower in HCC and its level was associated with tumor size. When we detected the expression of Homer1 in HCC peripheral blood, we discovered that Homer1was downregulated in HCC compared to cirrhosis, hepatitis B and the controls. ROC curve showed that Homer1 had a good diagnostic value to differentiate HCC from normal person and the combination of Homer1 and AFP would achieve better diagnostic accuracy. These findings for the first time revealed that the expression of Homer1 could be used as a novel diagnostic marker for HCC. However, large-scale studies are needed to confirm our findings and further investigations are still essential to explore the exact molecular mechanism of unregulated expression of Homer1 HCC.

\section{Acknowledgments}

This study was supported by the Research of Homer ELISA Kit for Breast Cancer (201260523173-2) and National Basic Research Program of China (973 Program) (2012CB720605).

\section{Competing Interests}

The authors have declared that no competing interest exists.

\section{References}

1. Tian $\mathrm{J}, \mathrm{Hu} \mathrm{X}, \mathrm{Gao} \mathrm{W}$, et al. Identification a novel tumor-suppressive hsa-miR-599 regulates cells proliferation, migration and invasion by targeting oncogenic MYC in hepatocellular carcinoma. Am J Transl Res. 2016; 8: 2575-84.

2. Fernandez-Rodriguez CM, Gutierrez-Garcia ML. Prevention of hepatocellular carcinoma in patients with chronic hepatitis B. World J Gastrointest Pharmacol Ther. 2014; 5: 175-82

3. Waghray A, Murali AR, Menon KN. Hepatocellular carcinoma: From diagnosis to treatment. World J Hepatol. 2015; 7: 1020-9.

4. Chen KW, Ou TM, Hsu CW, et al. Current systemic treatment of hepatocellular carcinoma: A review of the literature. World J Hepatol. 2015; 7 : 1412-20.

5. Quagliata L, Matter MS, Piscuoglio S, et al. Long noncoding RNA HOTTIP/HOXA13 expression is associated with disease progression and predicts outcome in hepatocellular carcinoma patients. Hepatology. 2014; 59: 911-23

6. Chen S, Chen H, Gao S, et al. Differential expression of plasma miR-125b in hepatitis B virus related liver diseases and diagnostic potential for hepatitis B virus induced hepatocellular carcinoma. Hepatol Res. 2016

7. Collier J, Sherman M. Screening for hepatocellular carcinoma. Hepatology. 1998; 27: 273-8.

8. Han LL, Lv $\mathrm{Y}$, Guo $\mathrm{H}$, et al. Implications of biomarkers in human hepatocellular carcinoma pathogenesis and therapy. World J Gastroenterol. 2014; 20: 10249-61.

9. Qi J, Wang J, Katayama H, et al. Circulating microRNAs (cmiRNAs) as novel potential biomarkers for hepatocellular carcinoma. Neoplasma. 2013; 60: 135-42.

10. Tu JC, Xiao B, Yuan JP, et al. Homer binds a novel proline-rich motif and links group 1 metabotropic glutamate receptors with IP3 receptors. Neuron. 1998; 21: $717-26$.
11. Jing $X$, Chen SS, Jing W, et al. Diagnostic potential of differentially expressed Homer1, IL-1beta, and TNF-alpha in coronary artery disease. Int J Mol Sci. 2015; 16: 535-46.

12. Brakeman PR, Lanahan AA, O'Brien R, et al. Homer: a protein that selectively binds metabotropic glutamate receptors. Nature. 1997; 386: 284-8.

13. Duncan RS, Hwang SY, Koulen P. Effects of Vesl/Homer proteins on intracellular signaling. Exp Biol Med (Maywood). 2005; 230: 527-35.

14. Berridge MJ, Bootman MD, Roderick HL. Calcium signalling: dynamics, homeostasis and remodelling. Nat Rev Mol Cell Biol. 2003; 4: 517-29.

15. Wen L, Liang C, Chen E, et al. Regulation of Multi-drug Resistance in hepatocellular carcinoma cells is TRPC6/Calcium Dependent. Sci Rep. 2016; 6: 23269.

16. Yuan JP, Kiselyov K, Shin DM, et al. Homer binds TRPC family channels and is required for gating of TRPC1 by IP3 receptors. Cell. 2003; 114: 777-89.

17. Jardin I, Albarran L, Bermejo N, et al. Homers regulate calcium entry and aggregation in human platelets: a role for Homers in the association between STIM1 and Orai1. Biochem J. 2012; 445: 29-38.

18. Kim JY, Zeng W, Kiselyov $\mathrm{K}$, et al. Homer 1 mediates store- and inositol 1,4,5-trisphosphate receptor-dependent translocation and retrieval of TRPC3 to the plasma membrane. J Biol Chem. 2006; 281: 32540-9.

19. Luo P, Li X, Fei Z, et al. Scaffold protein Homer 1: implications for neurological diseases. Neurochem Int. 2012; 61: 731-8.

20. Wu YL, Wang NN, Gu L, et al. The suppressive effect of metabotropic glutamate receptor 5 (mGlu5) inhibition on hepatocarcinogenesis. Biochimie. 2012; 94: 2366-75.

21. Wu SY, Yu MX, Li XG, et al. Identification of Homer1 as a potential prognostic marker for intrahepatic cholangiocarcinoma. Asian Pac J Cancer Prev. 2014; 15: 3299-304.

22. Shin JN, Piya S, Yun CW, et al. Homer1 regulates the susceptibility to TRAIL. Exp Cell Res. 2009; 315: 2249-55.

23. Matsumura M, Ijichi $M$, Shiratori $Y$, et al. Simple quantitative assay of alpha-fetoprotein mRNA in liver tissue using the real-time detection polymerase chain reaction assay - its application for clinical use. Hepatol Res. 2001; 20: 84-96.

24. Li C, Chen J, Zhang K, et al. Progress and Prospects of Long Noncoding RNAs (lncRNAs) in Hepatocellular Carcinoma. Cell Physiol Biochem. 2015; 36: 423-34.

25. Li J, Wang X, Tang J, et al. HULC and Linc00152 Act as Novel Biomarkers in Predicting Diagnosis of Hepatocellular Carcinoma. Cell Physiol Biochem. 2015; 37: 687-96.

26. Jang ES, Jeong SH, Kim JW, et al. Diagnostic Performance of Alpha-Fetoprotein, Protein Induced by Vitamin K Absence, Osteopontin, Dickkopf-1 and Its Combinations for Hepatocellular Carcinoma. PLoS One. 2016; 11: e0151069.

27. Liu Z, Hao C, Huang $X$, et al. Peripheral blood leukocyte expression level of IncRNA steroid receptor RNA activator (SRA) and its association with polycystic ovary syndrome: a case control study. Gynecol Endocrinol. 2015; 31: 363-8.

28. Berasain C, Castillo J, Perugorria MJ, et al. Inflammation and liver cancer: new molecular links. Ann N Y Acad Sci. 2009; 1155: 206-21.

29. Ito $Y$, Sasaki Y, Horimoto M, et al. Activation of mitogen-activated protein kinases/extracellular signal-regulated kinases in human hepatocellular carcinoma. Hepatology. 1998; 27: 951-8.

30. Xin $W$, Rhodes DR, Ingold $C$, et al. Dysregulation of the annexin family protein family is associated with prostate cancer progression. Am J Pathol. 2003; 162: 255-61.

31. Chen W, Chen L, Cai Z, et al. Overexpression of annexin A4 indicates poor prognosis and promotes tumor metastasis of hepatocellular carcinoma. Tumour Biol. 2016; 37: 9343-55.

32. Ni HM, Baty CJ, Li N, et al. Bid agonist regulates murine hepatocyte proliferation by controlling endoplasmic reticulum calcium homeostasis. Hepatology. 2010; 52: 338-48.

33. El Boustany C, Bidaux G, Enfissi A, et al. Capacitative calcium entry and transient receptor potential canonical 6 expression control human hepatoma cell proliferation. Hepatology. 2008; 47: 2068-77. 